\title{
Risk factors for extensive ulcerative colitis and ulcerative proctitis: a population based case-control study
}

\author{
S-M Samuelsson, A Ekbom, M Zack, C G Helmick, H-O Adami
}

\begin{abstract}
To examine socioeconomic factors, dietary and other personal habits, and medical history as risk factors for ulcerative colitis, we studied $167(98 \%)$ of all prevalent cases of ulcerative colitis diagnosed in Uppsala county from 1945 to 1964 and 167 age and sex matched population controls. Ulcerative colitis patients were less likely than controls to be current cigarette, pipe, or cigar smokers (odds ratio $(O R)=0.44$; $95 \%$ coinfidence limits $(C L)=0 \cdot 25-0.78)$, but more likely to have symptoms induced by drinking milk $(O R=4 \cdot 63 ; 95 \% C L=2 \cdot 15-9 \cdot 93)$. Patients with ulcerative colitis do not differ in most of the socioeconomic, dietary and personal habits compared with the background population.
\end{abstract}

The aetiology of ulcerative colitis is unknown, but previous case-control studies have suggested as determinants changes in diet, ${ }^{1}$ smoking, ${ }^{2-6}$ socioeconomic status, ${ }^{78}$ and childhood events such as infections and early weaning. ${ }^{89}$ The results in the different studies have been contradictory, and none was population based.

In an epidemiological investigation carried out in central Sweden about 20 years ago, all 220 patients diagnosed with ulcerative colitis in one county from 1945 to 1964 were identified. A total of 170 patients were alive on 1 January 1967 , and $167(98 \cdot 2 \%)$ volunteered to take part in a casecontrol study. This study investigated socioeconomic background, dietary, personal habits, and medical history. Information was also gathered on the progress and activity of the disease. The results were based on univariate summary statistics and were published as a thesis monograph. ${ }^{10}$ We have reanalysed these data using modern univariate and multivariate statistical methods for case-control studies. We also examined the presence of any differences between non-progressive ulcerative proctitis and more extensive ulcerative colitis.

\section{Methods}

PATIENTS

Uppsala County had a population of 146000 in 1945 and 180000 in 1964. Four hospitals within the County provided inpatient care during this period.

For the period 1945-1964 one of us (S-M S) retrieved and examined patient charts in all four hospitals with the following discharge diagnoses: chronic ulcerative colitis, ulcerative enterocolitis, ulcerative proctitis, non-ulcerative gastroenteritis and colitis, terminal ileitis, regional enteritis, diverticulitis of the colon, diverticulosis of the colon, unspecified diverticulitis, other colitis, severe colitis, chronic colitis, and chronic enterocolitis. At the major medical centre, the University Hospital in Uppsala, S-M S also examined an outpatient register for possible cases during this period. Finally, reports of all barium enemas carried out during the period in the three different radiography departments within the County were examined.

The medical history was reviewed in all cases meeting the diagnostic criteria for ulcerative colitis described by Evans and Acheson. ${ }^{11}$ Initially, 227 patients were identified with ulcerative colitis. A reevaluation of the diagnoses was done in 1970 because of a study of Crohn's disease in the same county ${ }^{12}$; in seven patients diagnoses of ulcerative colitis were changed to Crohn's disease leaving 220 patients. Almost every patient alive in 1967 underwent a medical examination, a sigmoidoscopy, and a barium enema, and 167 of the $170(98 \%)$ eligible cases volunteered to take part in the case-control study.

\section{CONTROLS}

For each of these 167 patients, one control was selected from the population in Uppsala County and matched to the case by sex, age (three years), marital status at the time of onset of symptoms, and place of residence (urban or rural) in 1967.

The records of all Swedish inhabitants are kept by the church, including both members and non-members. Each parish keeps records of all individuals living within their boundaries. By using five different parish registries we were able to select the controls by the criteria described above. In eight instances $(4 \cdot 6 \%)$ the first selected control refused to take part in the study and was replaced.

\section{DATA ELEMENTS}

Through the patient charts and registers within the County, information was gathered for each case on gender, year of onset of symptoms, year of diagnosis, place of residence at time of onset of symptoms and in 1967, extent of disease at time of diagnosis, maximum extent of disease until 1967 , extent of disease in 1967 , and number of days hospitalised because of ulcerative colitis and other illnesses after diagnosis.

Through face to face interviews with patients and controls, information was gathered about socioeconomic status of the father at time of 
birth, marital status of parents, birth order, number of siblings, weaning, educational level, grade in mathematics during the last year in school, age at menarche, fitness for military duty, marital status, age at marriage, number of children before and after onset of symptoms, socioeconomic status and living conditions one year before onset of symptoms (the reference year for the matched control) and in 1967, diseases other than ulcerative colitis, number of days hospitalised and number of days of sick leave for ulcerative colitis and other diseases, smoking habits in 1967, age when starting smoking, drinking habits in 1967, and information about milk consumption in 1967. Socioeconomic status was classified as upper, middle, and lower and analysed for linear trend. To get an equivalent measurement in grams of total alcohol consumption per month, the number of bottles of beer, the number of glasses of wine, and the number of centilitres of hard liquor divided by 4.43595 were added.

To test the hypothesis that ulcerative proctitis and extensive ulcerative colitis have different aetiologies, ${ }^{13}$ we distinguished those designated as non-progressive proctitis among the cases where the colitis never had extended beyond the rectosigmoid junction from all other ulcerative colitis cases.

\section{STATISTICAL ANALYSIS}

The main measure of effect for a specific exposure in this study is the odds ratio (OR), an approximation to the relative risk that compares the odds of being exposed among cases to that among controls. ${ }^{14}$ For the matched case-control comparisons we used conditional logistic regression to estimate the odds ratio and its asymptotic $95 \%$ confidence limits $(95 \% \mathrm{CL})$. We have expressed for some continuous variables the limits that include $95 \%$ of a population as $95 \%$ tolerance limits (95\% TL). ${ }^{15}$ In these matched comparisons, we also used a randomised block design to analyse the effects of some continuous exposure variables without splitting them into arbitrary categories. ${ }^{16}$ In our multivariate analysis, we initially included all variables with $\mathrm{p} \leq \mathbf{0 . 2 5}$ in order not to miss possible confounding effects.

An association between case-control status and an exposure variable whose $95 \% \mathrm{CL}$ of the OR exclude 1.00 or whose significance probability is less than or equal to 0.05 is considered statistically significant.

\section{Results}

\section{FEATURES OF PATIENTS}

Of the 220 patients, 50 died; this should be compared with an expected mortality of 29 patients using mortality data for the equivalent age groups during the time period studied in Sweden. Eleven patients died within two months of diagnosis; four of these died after surgical intervention. On death certificates for 30 cases, ulcerative colitis is not mentioned. In five patients, the diagnosis of ulcerative colitis occurs with a diagnosis of colorectal cancer. In two patients the diagnosis of ulcerative colitis occurs with liver disease, and in another, ulcerative colitis occurs with amyloidosis. In one 86 year old patient the cause of death was ulcerative proctitis. Finally, three patients, where the cause of death was ulcerative colitis, died at home without medical supervision.

Of the 167 patients 87 (52\%) were male. At time of interview, on average 13 years $(95 \% \mathrm{TL}=$ 4 to 35 ) had elapsed since the first attack of either diarrhoea or bloody stools indicating in some instances a substantial lag between the first attack and a subsequent diagnosis of ulcerative colitis. The median age at which patients started diarrhoea was 27 years ( $96 \% \mathrm{TL}=4$ to 61$)$, the same median age as those started having bloody stools $(95 \% \mathrm{TL}=4$ to 61$)$. The age at which the patients started having diarrhoea was usually the same as when they started having bloody stools, but in $7 \%$ the diarrhoea preceded the onset of bloody stools by at least one year, and in $5 \%$ the reverse occurred.

The first hospital admission for ulcerative colitis occurred on average four years after onset (the median age at first hospital admission $=31$ with $95 \% \mathrm{TL}=4$ to 69 ). At first admission, $79 \%$ were considered only mildly affected, and only one patient required an operation. More than half of the 161 patients who underwent radiological examination without an operation had disease confined to the rectum at diagnosis. For those with limited disease at diagnosis, however, the extent of disease did increase after onset because only $38 \%$ had their disease confined to the rectum at its maximal extent. Almost $90 \%$ of the cases achieved complete remission or improved before discharge.

\section{CASE-CONTROL ANALYSIS}

Characteristics of the individual and of the family background did not generally distinguish the ulcerative colitis cases from their unaffected controls (Table I). Patients did not differ from controls with respect to birth order, how soon they were weaned, the number of siblings, their being or not being raised by both parents, or paternal (childhood) socioeconomic status. Patients had completed high school slightly but not statistically significantly more often than controls but still considered themselves more in need of further schooling $(\mathrm{OR}=3 \cdot 67,95 \% \mathrm{CL}=$ $1 \cdot 02-13 \cdot 14)$. Patients did not have higher math grades at school than controls, nor did male patients have lower military fitness rankings than their controls. Female patients (mean age $13 \cdot 8$ years) did not differ from their controls (mean age 13.7 years $p=0.62$ ) with respect to age at menarche.

The socioeconomic status, marital status, number of children, and degree of crowding within their homes (the number of persons per room) was not significantly associated with the occurrence of ulcerative colitis. Age at marriage was not delayed in cases (mean age $=25 \cdot 1$ years) relative to that in controls (mean age $=25.8$ years; $\mathrm{p}=0.75$ ). Patients were, however, more likely to have a rural residence compared with controls one year before onset of disease $(\mathrm{OR}=0.50 ; 95 \%$ $\mathrm{CL}=0 \cdot 28-0 \cdot 90$ ) (Table II). 
TABLE I Characteristics during childhood and adolescence ${ }^{\star}$

\begin{tabular}{|c|c|c|c|}
\hline Characteristic & All patients & $\begin{array}{l}\text { Extensive } \\
\text { ulcerative colitis }\end{array}$ & $\begin{array}{l}\text { Non-progressive } \\
\text { ulcerative proctitis }\end{array}$ \\
\hline Birth order & $1.01(0.92-1 \cdot 12)$ & $1.00(0 \cdot 88-1 \cdot 11)$ & $1.06(0.89-1 \cdot 25)$ \\
\hline Weaned before 14 days & $1.20(0 \cdot 31-2 \cdot 78)$ & $1.00(0.35-2.86)$ & $1.67(0.40-6.98)$ \\
\hline Siblings (n) & $1.05(0.96-1.14)$ & $1.04(0.93-1 \cdot 17)$ & $1.06(0.93-1.21)$ \\
\hline Brought up without both parents & $0.83(0.50-1.36)$ & $0.61(0.31-1 \cdot 19)$ & $1.17(0.53-2.53)$ \\
\hline Paternal socioeconomic status & & & \\
\hline Middle $v$ high status & $0.87(0.41-1 \cdot 86)$ & $0.58(0.21-1 \cdot 57)$ & $2.80(0.56-13.88)$ \\
\hline Low $v$ high status & $0.66(0.30-1.42)$ & $0.27(0.09-0.75) \dagger$ & $6 \cdot 13(1 \cdot 08-34 \cdot 53) \dagger$ \\
\hline Completed high school & $1 \cdot 31(0.63-2 \cdot 70)$ & $2.00(0.80-4.96)$ & $0.50(0.12-2.00)$ \\
\hline Felt need of further schooling & $3.67(1.02-13 \cdot 14) \dagger$ & $4.00(0.84-18.84)$ & $3.00(0.31-28 \cdot 82)$ \\
\hline School math scores & $1.09(0.72-1.65)$ & $0.83(0.48-1.43)$ & $1.54(0.79-2.98)$ \\
\hline Unfit for normal military duty (men) & $1.54(0 \cdot 76-3 \cdot 10)$ & $1.63(0.67-3.93)$ & $1.40(0.44 .4 .42)$ \\
\hline
\end{tabular}

$\star$ Odds ratios and $95 \%$ confidence limits of odds ratios; tbecause the $95 \%$ confidence limits of the odds ratio do not include 1.00 , the observed association between this variable and disease is statistically significant at the 0.05 significance level.

TABLE II Characteristics at one year before onset *

\begin{tabular}{|c|c|c|c|}
\hline Characteristic & All cases & $\begin{array}{l}\text { Extensive } \\
\text { ulcerative colitis }\end{array}$ & $\begin{array}{l}\text { Non-progressive } \\
\text { ulcerative proctitis }\end{array}$ \\
\hline \multicolumn{4}{|l|}{ Socioeconomic status } \\
\hline Middle $v$ high status & $0.56(0.24-1.42)$ & $0.53(0 \cdot 19-1 \cdot 42)$ & $1 \cdot 12(0 \cdot 17-7 \cdot 02)$ \\
\hline Low $v$ high status & $0.56(0.24-1.33)$ & $0.32(0.11-0.90) \dagger$ & $2.44(0.37-16.04)$ \\
\hline Not married & $3.50(0.72-16.85)$ & $6.00(0.72-49.84)$ & $1.00(0.06-15.99)$ \\
\hline Children (n) & $0.85(0.66-1.10)$ & $0.90(0.66-1.22)$ & $0 \cdot 77(0 \cdot 48-1 \cdot 23)$ \\
\hline$>1$ person/room (residence) & $1 \cdot 11(0 \cdot 70-1 \cdot 76)$ & $0.85(0.48-1.49)$ & $2.00(0.85-4.68)$ \\
\hline Urban $v$ rural residence & $0.50(0.28-0.90) \dagger$ & $0.69(0 \cdot 31-1 \cdot 49)$ & $0.31(0.11-0.86) \dagger$ \\
\hline
\end{tabular}

*Odds ratios and $95 \%$ confidence limits of odds ratios; tbecause the $95 \%$ confidence limits of the odds ratio do not include $1 \cdot 00$, the observed association between this variable and disease is statistically significant at the 0.05 significance level.

Patients were less likely than controls to be current cigarette smokers in $1967(\mathrm{OR}=0.51$; 95\% CL $=0 \cdot 29-0 \cdot 87$ ) but were as likely as controls to have been a former cigarette smoker $(\mathrm{OR}=1 \cdot 12,95 \% \mathrm{CL}=0 \cdot 55-2 \cdot 29)$. Among ever smokers of cigarettes, patients began smoking at about the same age as controls, but current smokers smoked slightly fewer cigarettes per day than controls $(\mathrm{OR}=0.95,95 \% \mathrm{CL}=0.90-0.99)$. Patients were less likely than controls to be current smokers of either cigarettes, pipe or cigars $(\mathrm{OR}=0 \cdot 44,95 \% \mathrm{CL}=0 \cdot 25-0 \cdot 78)$; patients resembled controls with respect to being a

TABLE III Characteristics at interview*

\begin{tabular}{|c|c|c|c|}
\hline Characteristic & All cases & $\begin{array}{l}\text { Extensive } \\
\text { ulcerative colitis }\end{array}$ & $\begin{array}{l}\text { Non-progressive } \\
\text { ulcerative proctitis }\end{array}$ \\
\hline \multicolumn{4}{|l|}{ Smoking habits } \\
\hline \multicolumn{4}{|l|}{ Current cigarette smoker $v$} \\
\hline non-smoker & $0.51(0.29-0.87) \dagger$ & $0.47(0.23-0.93) \dagger$ & $0.63(0.25-1.56)$ \\
\hline Excigarette smoker $v$ non-smoker & $1 \cdot 12(0 \cdot 55-2 \cdot 29)$ & $0.90(0.39-2.06)$ & $2 \cdot 14(0 \cdot 49-9 \cdot 22)$ \\
\hline Cigarettes smoked/day (n) & $0.95(0.90-0.99) \dagger$ & $0.94(0.88-1.00)$ & $0.96(0.90-1.02)$ \\
\hline Current smokers & $0.44(0.25-0.78) \dagger$ & $0.41(0.20-0.82) \dagger$ & $0.54(0.19-1.52)$ \\
\hline Exsmokers & $0.96(0.46-1.99)$ & $0.90(0.38-2 \cdot 08)$ & $1 \cdot 21(0 \cdot 27-5 \cdot 25)$ \\
\hline \multicolumn{4}{|l|}{ Beverage consumption } \\
\hline Symptoms after drinking milk & $4.63(2 \cdot 15-9.93) \dagger$ & $8.67(2 \cdot 62-28 \cdot 64) \dagger$ & $2 \cdot 00(0 \cdot 68-5 \cdot 86)$ \\
\hline Glasses of milk/week (n) & $0.97(0.94-0.99) \dagger$ & $0.95(0.92-0.99) \dagger$ & $1.00(0.96-1.04)$ \\
\hline Bottles of beer/month (n) & $1.00(0.98-1.02)$ & $1.00(0.97-1.02)$ & $1.01(0.97-1.04)$ \\
\hline Glasses of wine/month (n) & $0.98(0.94-1.02)$ & $1.00(0.95-1.04)$ & $0.93(0.85-1.02)$ \\
\hline Centilitres hard liquor/month & $0.99(0.98-1.00)$ & $1.00(0.99-1.01)$ & $0.98(0.96-1.01)$ \\
\hline
\end{tabular}

* Odds ratios and $95 \%$ confidence limits of odds ratios; †because the $95 \%$ confidence limits of the odds ratio do not include 1.00 , the observed association between this variable and disease is statistically significant at the 0.05 significance level.

TABLE IV Multiple characteristics *

\begin{tabular}{|c|c|c|c|}
\hline Characteristic & All cases & $\begin{array}{l}\text { Extensive } \\
\text { ulcerative colitis }\end{array}$ & $\begin{array}{l}\text { Nom-progressive } \\
\text { ulcerative proctitis }\end{array}$ \\
\hline $\begin{array}{l}\text { Urban } v \text { rural residence } \\
\text { Current cigarette smoker } v \text { non-smoker } \\
\text { Excigarette smoker } v \text { non-smoker } \\
\text { Symptoms after drinking milk }\end{array}$ & $\begin{array}{l}0.53(0.27-1.00) \dagger \\
0.53(0.29-0.94) \dagger \\
0.76(0.35-1.63) \\
4.31(1.94-9.57) \dagger\end{array}$ & $\begin{array}{l}0.89(0 \cdot 38-2 \cdot 08) \\
0 \cdot 50(0 \cdot 23-1 \cdot 06) \\
0 \cdot 58(0 \cdot 23-1 \cdot 45) \\
8 \cdot 90(2 \cdot 60-30 \cdot 36) \dagger\end{array}$ & $\begin{array}{l}0.31(0.10-0.91) \dagger \\
0.56(0.21-1.47) \\
1.22(0.25-5 \cdot 94) \\
1.90(0.56-6.34)\end{array}$ \\
\hline
\end{tabular}

*Odds ratios and $95 \%$ confidence limits of odds ratios; †because the $95 \%$ confidence limits of the odds ratio do not include $1 \cdot 00$, the observed association between this variable and disease is statistically significant at the 0.05 significance level. former smoker of cigarettes, pipe, or cigars $(\mathrm{OR}=0.96,95 \% \mathrm{CL}=0.46-1.99)$. At the time of interview (1967), patients complained more often than controls of having symptoms after drinking milk $(\mathrm{OR}=4 \cdot 63 ; 95 \% \mathrm{CL}=2 \cdot 15-9 \cdot 39)$ and reported drinking fewer glasses of milk per week (median 7) than controls (median 14). Patients drank about the same amount of alcohol (beer, wine, or hard liquor) as controls (Table III).

In a multivariate analysis, urban/rural status one year before onset of disease, smoking status, and whether there were symptoms after drinking milk at the time of interview remained statistically significant (Table IV). Their adjusted odds ratios did not differ from those in the univariate analysis; urban residence status a year before onset ( $\mathrm{OR}=0.53,95 \% \mathrm{CL}=0 \cdot 27-1 \cdot 00)$, current smokers $(\mathrm{OR}=0.53,95 \% \mathrm{CL}=0.29-0.94)$, and symptoms after drinking milk $(\mathrm{OR}=4 \cdot 31,95 \%$ $\mathrm{CL}=1 \cdot 94-9 \cdot 57)$.

\section{COMPARISON OF NON-PROGRESSIVE ULCERATIVE} PROCTITIS CASES TO EXTENSIVE ULCERATIVE COLITIS CASES

In the Tables the results are also stratified by extent of disease. An unmatched comparison was also made between the two groups. Of the $\mathbf{1 7 0}$ cases of ulcerative colitis, 64 (38\%) had nonprogressive ulcerative proctitis (considered the comparison group) and 106 extensive ulcerative colitis (considered the case group). Slightly but not significantly more women than men had extensive ulcerative colitis $(O R=1.37 ; 95 \%$ $\mathrm{CL}=0.73-2.57)$. The median age at onset of symptoms (diarrhoea) was about the same in patients with extensive ulcerative colitis (26 years) and ulcerative proctitis (28 years; $p=0.63$ ). Patients with extensive ulcerative colitis spent more time hospitalised (median $=125$ days) than the ulcerative proctitis cases (median $=85$ days; $\mathrm{p}=0.027$ ) from the time of diagnosis up to 1967 . This was entirely as a result of the colitis, as cases with ulcerative proctitis were hospitalised more days for other reasons (median $=24.5$ days) than extensive ulcerative colitis cases (median $=11$ days; $p=0 \cdot 01$ ). Extensive ulcerative colitis cases had been operated on more often than the ulcerative proctitis cases $(\mathrm{OR}=2 \cdot 74,95 \%$ $\mathrm{CL}=0 \cdot 97-7 \cdot 72$ ), but not significantly so.

The socioeconomic status of the fathers of extensive ulcerative colitis patients was higher than that of the ulcerative proctitis cases. The same difference was also evident when socioeconomic status was treated as a linear variable with scores ( 1 high, 2 middle, 3 low). Extensive ulcerative colitis cases had also completed high school more often than ulcerative proctitis cases. Extensive ulcerative colitis cases, however, did not differ from ulcerative proctitis cases with respect to birth order or the number of siblings.

In the year before onset, the extensive ulcerative colitis patients closely resembled those with ulcerative proctitis with respect to place of residence (urban versus rural), marital status, and number of children. Age at marriage for those who married did not differ between the groups. The socioeconomic status, however, was higher among extensive ulcerative colitis 
patients compared with those with ulcerative proctitis when treated as a linear variable.

Extensive ulcerative colitis patients were less likely than those with ulcerative proctitis to be current smokers of cigarettes, pipe, or cigars; among ever smokers, age at onset of smoking did not differ between the groups. Extensive ulcerative colitis patients were less likely to be former smokers than were ulcerative proctitis patients.

At the time of interview, extensive ulcerative colitis patients reported having symptoms after drinking milk more often than ulcerative proctitis patients, though the number of glasses of milk drunk per week did not differ between the two groups.

Extensive ulcerative colitis patients did not drink more beer, hard liquor, or total alcohol than ulcerative proctitis patients. Extensive ulcerative colitis patients were, however, more likely to be wine drinkers than those with ulcerative proctitis.

\section{Discussion}

Our main finding was the absence of differences between patients with ulcerative colitis and population controls regarding most socioeconomic factors, and personal habits before and after diagnosis. Patients were more likely, however, to have a rural residence before diagnosis. After diagnosis, patients were less likely to be current smokers and more likely to have symptoms after drinking milk. Patients with nonprogressive ulcerative proctitis did not differ from those with extensive ulcerative colitis with respect to most variables.

This study is, to the best of our knowledge, the only population based case-control study of ulcerative colitis published so far. Almost all eligible patients and controls in the defined population were included, making selection bias unlikely. The retrospective methodology used to ascertain exposure may have introduced biases. The disease itself may have changed personal habits. Information regarding smoking and other personal habits was gathered in 1967 and habits at time of interview were analysed most often. In the few instances where information was gathered about habits before disease onset two to 22 years earlier, recall bias could be a problem. Incident cases who died before 1967, 50 of $220(23 \%)$, were not included in this study. This fact could bias our results for risk factors such as smoking, which entails an excess mortality rate leading to an underestimation of the relative risk. The impact of this is, however, less than the number of 50 would lead us to believe. There was an expected number of 29 deaths among our patients which is close to that given in the death certificates. This means that the differential misclassification is likely to affect about 20 of the 220 patients being incident cases. Interview bias is unlikely because the interviewer (S-M S) did not have any previous hypotheses.

Three previous case-control studies have addressed the relationship of childhood events and ulcerative colitis. ${ }^{7-9}$ In most respects these results agree with ours. In the case of weaning, however, our study showed no difference between cases and controls, but two of the other studies showed a decreased proportion of breast feeding among future ulcerative colitis patients. ${ }^{89}$ The 'sheltered child' hypothesis has been proposed for ulcerative colitis, but has never been proved'; and as in two previous studies, ${ }^{79}$ our patients did not differ from their controls in the number of siblings, birth order, or number of persons per room.

Two previous studies analysed urban/rural status at the time of diagnosis. ${ }^{117} \mathrm{One}^{11}$ found a higher risk of ulcerative colitis among urban residents, but the other ${ }^{17}$ failed to detect any difference. Because our patients and controls were matched on urban/rural status at follow up, our results seem to indicate that patients with ulcerative colitis more often emigrate to urban areas after diagnosis compared with the general population. This finding casts some doubt on the hypothesis that urban residence is a risk factor for ulcerative colitis.

The absence of differences between patients and controls in alcohol consumption and marital status concurs with the results from another case-control study. ${ }^{18}$ In that study,${ }^{18}$ patients had a higher educational level than controls, which agrees with our results for extensive ulcerative colitis but not for non-progressive ulcerative proctitis. The proportion of cases with more extensive disease, however, seems to be higher in that study than in ours, which could explain the differences.

Our study is to our knowledge the earliest that addressed the association between non-smoking and ulcerative colitis. After the first published study in $1982,{ }^{2}$ many reports confirmed nonsmoking as a feature of patients with ulcerative colitis. If the interviewer knows the study hypothesis and the case-control status of the person being interviewed, then this might bias a currently performed study. In our study, however, information was gathered in 1967, before the hypothesis that smoking offers protection from developing ulcerative colitis was formulated.

The lower proportion of current smokers among patients compared with the background population agrees with findings in previously published reports. ${ }^{2-6}$ The similar proportion of exsmokers among patients and controls in our study, however, disagrees with those findings..$^{2-6}$ Perhaps physicians in the 1960s less often advised against smoking than more recently. This would imply that exsmoking status as a risk factor for ulcerative colitis is not as strong as previously thought. A genetic predisposition to ulcerative colitis and ulcerative proctitis but against cigarette smoking may also explain the differences in smoking habits.

Our result of a higher proportion of patients having symptoms induced by drinking milk after diagnosis compared with controls agrees with that in a study by Wright. ${ }^{1}$ In a study by Gilat, however, no such association was found, but the fact that their controls were partly hospital based, sometimes because of different gastrointestinal disorders, could explain their different finding. The increased level of serum antibodies to cow's milk proteins reported among ulcerative colitis patients ${ }^{19}$ hints at a biological mechanism 
behind our finding. Lactose intolerance secondary to the ulcerative colitis may also explain this finding.

Most comparisons between non-progressive ulcerative proctitis and extensive ulcerative colitis did not yield any differences. Fathers of extensive colitis patients had a higher socioeconomic status, however, than those of nonprogressive ulcerative colitis cases. This finding could explain the different results in different studies analysing parents' socioeconomic status, ${ }^{7-9}$ making the assumption that the proportion of extensive ulcerative colitis and nonprogressive ulcerative proctitis differ in most studies. Moreover, as in one previous study ${ }^{20}$ extensive ulcerative colitis patients were less likely to be current smokers. On the other hand, extensive ulcerative colitis patients were less likely to be exsmokers compared with nonprogressive ulcerative proctitis cases. This association could either be explained by smoking as a protective agent against ulcerative colitis or that patients with extensive ulcerative colitis are more likely never to start smoking, conceivably because the disease is systemic and also involves the lungs. Extensive ulcerative colitis patients also seem to have a higher proportion of those having symptoms after drinking milk than nonprogressive ulcerative proctitis cases.

Total alcohol consumption did not differ between the two groups and the difference in wine consumption could be caused by chance, as a biological explanation is difficult to formulate. Our finding of an increased number of days in the hospital because of diseases not related to ulcerative colitis is also hard to explain. One feasible explanation could be that when patients with an extensive colitis are hospitalised for any other disease, the treating physician's main concern will still be the colitis, leading to a discharge code for ulcerative colitis.

The findings in our comparison between extensive colitis and non-progressive ulcerative proctitis are not so strong that they confirm the hypothesis of ulcerative proctitis as a specific entity. ${ }^{13}$ On the other hand, certain differences between the two groups in our study make it premature to classify ulcerative proctitis entirely as a subgroup of ulcerative colitis. ${ }^{2122}$

Supported by grants from the National Foundation for Ileitis and Colitis. The authors thank Dr Richard Rothenburg for valuable support.

1 Wright R, Truelove SC. A controlled therapeutic trial of various diets in ulcerative colitis. BMF 1965; ii: $138-41$.

2 Harries AD, Baird A, Rhodes J. Non-smoking: a feature of ulcerative colitis. $B M \mathcal{F}$ 1982; 284: 706 .

3 Benoni C, Nilsson A. Smoking habits in patients with inflammatory bowel disease. Scand $\mathcal{f}$ Gastroenterol 1987; 22 $1130-6$

4 Boyko EJ, Koepsell TD, Perera DR, Inui TS. Risk of ulcerative colitis among former and current cigarette smokers. NEnglf Med 1987; 316: 707-10.

5 Lindberg E, Tysk C, Andersson K, Järnerot G. Smoking and inflammatory bowel disease. A case control study. Gut 1988; 29: 352-7.

6 Tobin MV, Logan RFA, Langman MJS, McConnell RB, Gilmore IT. Cigarette smoking and inflammatory bowel disease. Gastroenterology 1987; 93: 316-21.

7 Gilat T, Hacohen D, Lilos P, Langman MJS. Childhood factors in ulcerative colitis and Crohn's disease. Scand $\mathcal{F}$ Gastroenterol 1987; 22: 1009-24.

8 Whorwell PJ, Holdstock G, Whorwell GM, Wright R. Bottle feeding, early gastroenteritis and inflammatory bowel disease. $B M \mathcal{F}$ 1979; i: 382

9 Acheson ED, Truelove SC. Early weaning in the aetiology of ulcerative colitis. BMF 1961; ii: 929-33.

10 Samuelsson SM. Ulcerös colit och proctit Uppsala: Department of social medicine: University of Uppsala, 1976 (Thesis).

11 Evans JG, Acheson D. An epidemiological study of ulcerative colitis and regional enteritis in the Oxford area. Gut 1965; 6: 311-24.

12 Norlén BJ, Krause U, Bergman L. An epidemiological study of Crohn's disease. Scand F Gastroenterol 1970; 5: 385-90.

13 Ritchie JK, Hawley PR. Idiopathic proctitis. In: Allan RN, Keighley MRB, Alexander-Williams J, Hawkins C, eds. Inflammatory bowel disease. New York: ChurchillLivingstone, 1983.

14 Breslow NE, Day NE. Statistical methods in cancer research. Volume 1. The analysis of case-control studies. Lyon, France: International Agency for Research on Cancer, 1980: 69-73, 192-279.

15 Diem K, ed. Documents Geigy Scientific Tables. 6th ed. Ardsley, New York: Geigy Pharmaceuticals, 1962: 154.

16 SAS user's guide: statistics. Sth ed. Cary, North Carolina: SAS Institute Inc, 1985: 433-506, 607-14.

17 Shivananda S, Pena AS, Mayberry JF, Ruitenberg EJ, Hoedemaeker PJ. Epidemiology of proctocolitis in the region of Leiden, The Netherlands. Scand $\mathcal{F}$ Gastroenterol 1987; 22: 993-1002.

18 Hendriksen C, Binder V. Social prognosis in patients with ulcerative colitis. BMF 1980; 281: 581-3.

19 Lerner A, Rossi TM, Park B, Albini B, Lebenthal E. Serum antibodies to cow's milk proteins in pediatric inflammatory bowel disease. Crohn's disease vs ulcerative colitis. Acta Paediatr Scand 1989; 78: 81-6.

20 Boyko EJ, Perera DR, Koepsell TD, Keane EM, Inui TS. Effects of cigarette smoking on the clinical course of Effects of cigarette smoking on the clinical course of

21 Folley JH. Ulcerative proctitis. $N$ Engl $\mathcal{F}$ Med 1970; 282. $1362-4$.

22 Lennard-Jones JE, Cooper GW, Newell AC, Wilson CW, Avery Jones F. Observations on idiopathic proctitis. $G u$ 1962; 3: 201-6. 